\title{
Effect of Modifiers Introduced into Cold Phosphating Solutions on the Physical and Mechanical Properties of the Formed Phosphate Films
}

\author{
Viktoriya Konovalova ${ }^{1, *}$ \\ ${ }^{1}$ Ivanovo State Polytechnic University, Department of natural sciences and technosphere safety, \\ Sheremetevsky av., 21, Ivanovo, 153000, Russian Federation
}

\begin{abstract}
This work is devoted to the study of the physical-mechanical and protective properties of modified phosphate coatings obtained on steel by cold method. Modifiers introduced into phosphating solutions are buffer additives, stabilize the phosphating process, allow the deposition of coatings at low temperatures, increase the number of active centers on the metal surface, resulting in fine-crystalline uniform coatings of small thickness. It was found that the corrosion rate of modified phosphate films is 2 times less than that of coatings obtained by the traditional method. When the temperature rises above $100{ }^{\circ} \mathrm{C}$, the corrosion resistance of phosphate coatings decreases, and the satisfactory protective properties of the modified films are preserved when heated to $200{ }^{\circ} \mathrm{C}$. Modified phosphate coatings have a high adhesion strength to the metal due to their small thickness. However, thin phosphate coatings have low wear resistance and medium electrical insulation properties.
\end{abstract}

\section{Introduction}

Obtaining phosphate coatings on steel is one of the ways to protect the surface of the processed product from corrosion. Traditionally, phosphate films are obtained from solutions based on single-substituted orthophosphoric acid salts. To obtain phosphate coatings, singlesubstituted phosphates of divalent metals are used: manganese, iron, zinc, and cadmium [1]. For this purpose, the drug «Majef» is successfully used, which is a mixture of monosubstituted salts of orthophosphoric acid, iron and manganese: $\mathrm{Fe}\left(\mathrm{H}_{2} \mathrm{PO}_{4}\right)_{2}$, $\mathrm{Mn}\left(\mathrm{H}_{2} \mathrm{PO}_{4}\right)_{2} \cdot \mathrm{H}_{2} \mathrm{O}, \mathrm{MnHPO}_{4}$.

To accelerate the phosphating process, oxidizing agents are introduced into the solution, such as $\mathrm{NaNO}_{3}, \mathrm{NaNO}_{2}, \mathrm{Zn}\left(\mathrm{NO}_{3}\right)_{2}, \mathrm{KBrO}_{3}, \mathrm{KClO}, \mathrm{NaF}$ [2-5], which increases the speed of the cathodic process. Oxidizing agents, having a passivating effect, turn part of the anode sections into inactive cathode ones. As a result, the total area of the anode sections is reduced. Thus, the ratio between the cathode and the remaining active anode sites increases, which favors the cathode process and, consequently, forces the formation of the coating [2]. The

\footnotetext{
* Corresponding author: kotprotiv@yandex.ru
} 
addition of nitrite improves the quality of coatings. The operating temperature of the phosphating solution can be reduced in this case $[6,7]$.

Phosphate coatings have a high electrical resistance and can withstand a voltage of up to $1000 \mathrm{~V}$ [8]. The impregnation of phosphate coatings with oil and bakelite lacquers significantly increases the breakdown voltage.

In terms of hardness, the phosphate film is superior to copper and brass, but it is softer than steel. The adhesion strength of the phosphate film to the steel is very high [9]. However, when the phosphated iron sheet is bent by $180^{\circ}$, the phosphate film cracks and crumbles at the bending points, but does not peel off and does not allow further penetration of corrosion under the film [10].

The solubility of the phosphate film in water at room temperature is about $1,5 \mathrm{mg} / \mathrm{l}$, at 90 ${ }^{\circ} \mathrm{C}-10,6 \mathrm{mg} / \mathrm{l}$. In acids and alkalis, phosphate coatings are unstable [2]. The main valuable property of the phosphate film is its high corrosion resistance in all types of combustible, lubricating and organic oils, in benzene, toluene and in all gases except hydrogen sulfide [11, 12]. The protective ability of conventional phosphate coatings is higher than that of oxide films obtained by alkaline oxidation of steel $[13,14]$. Phosphate films are not wetted by molten metals.

Phosphate coatings can withstand short-term heating up to $400{ }^{\circ} \mathrm{C}$, at a higher temperature, the protective ability of the coating decreases. The heat resistance and electrical insulation properties of the films are maintained up to $600{ }^{\circ} \mathrm{C}$ [15].

The magnetic permeability of electrical steel grades is completely preserved during phosphating [16]. It does not change the phosphating and mechanical properties of the steel. The wear resistance of the phosphate film is not great [17]. An important property of phosphate films, especially after their impregnation with lubricating oils, is a significant reduction in friction during cold drawing, rolling and deep drawing of sheet steel [18].

\section{Materials and methods}

Before applying the coating, the samples made of steel grade St 3 were cleaned with coarsegrained, then with fine-grained sandpaper. The samples were degreased with an alcohol solution and with a solution heated to $60{ }^{\circ} \mathrm{C}$ containing soda and alkali for 30 seconds, then washed with distilled water. The phosphate coating was deposited at a temperature of 20-25 ${ }^{\circ} \mathrm{C}$ for 20 minutes, then the samples were washed with distilled water.

Phosphate coatings were obtained from a standard solution containing the drug «Majef» 30-40 g/l, $\mathrm{Zn}\left(\mathrm{NO}_{3}\right)_{2}$ 50-60 g/l and $\mathrm{NaNO}_{2} 3-4 \mathrm{~g} / \mathrm{l}$, and from solutions with modifiers (Table 1). The introduced organic additives maintain the $\mathrm{pH}$ of phosphating solutions in the required range of values, reduce sludge formation, reduce the porosity of deposited phosphate coatings, and improve their structure.

Table 1. Compositions of modified solutions of cold phosphating, g/l

\begin{tabular}{|c|c|c|}
\hline Components & Modified solution №1 & Modified solution №2 \\
\hline «Majef» & $30-40$ & $35-45$ \\
$\mathrm{Zn}\left(\mathrm{NO}_{3}\right)_{2}$ & $50-60$ & $50-65$ \\
$\mathrm{NaNO}_{2}$ & $3-4$ & $3-4$ \\
Glukose & $1-2$ & - \\
Glycerin & - & $1-2$ \\
Trilon A & $5-7$ & - \\
Trilon B & - & $6-8$ \\
OP-7 & $3-5$ & - \\
OP-10 & $3-5$ & - \\
OS-20 & - & $5-10$ \\
\hline
\end{tabular}


To check the protective properties, steel samples coated with phosphate films were tested by the drip method. A drop of a solution containing $80 \mathrm{~g} / 1$ of $\mathrm{CuSO}_{4} \cdot 5 \mathrm{H}_{2} \mathrm{O}, 33 \mathrm{~g} / \mathrm{l}$ of NaCl , and $13 \mathrm{ml} / 1$ of $\mathrm{HCl}(0,1 \mathrm{~N})$ was applied to the surface of the phosphate film, and after switching on the stopwatch, the color of the drop was monitored from blue to red due to contact deposition of copper during the interaction of the solution with steel in the pores of the coating.

The heat resistance of the modified coatings was checked at temperatures of 100, 200, and $300{ }^{\circ} \mathrm{C}$ by placing the samples in a muffle furnace for 2 minutes. After the samples were extracted and cooled, the protective ability of the phosphate films was checked by the drip method.

The determination of the adhesion strength of phosphate coatings to metal was carried out under shock load on the device shown in Fig. 1. The device allows to simultaneously characterize the impact strength of phosphate coatings.

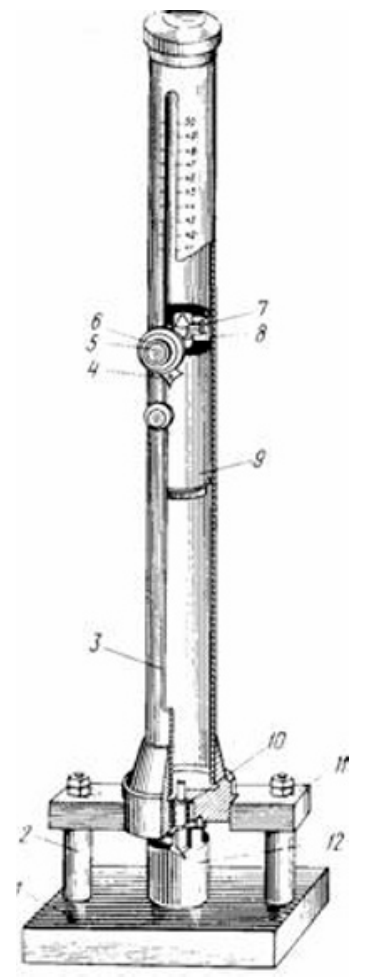

Fig. 1. Device for determining the strength of films on impact: 1 - frame; 2 - rack; 3 - guide tube; 4 pointer arrow; 5 - reset button; 6 - locking screw; 7 - stopper; 8 - body; 9 - load; 10 - striker; 11 traverse; 12 - anvil.

The test samples are prepared in the form of thin plates made of steel grade St3, coated with phosphate films from traditional and modified solutions of cold phosphating. In the center of the anvil there is a recess into which the sample enters when it is deformed by the impact of the striker. The shock load in the device is constant and is equal to $1 \mathrm{~kg}$. The drop height was $50 \mathrm{~cm}$.

The wear of phosphate coatings was carried out on the installation for determining the coefficient of friction. The friction scheme is disk by disk. The rotating disc with a diameter of $0,04 \mathrm{~m}$ is made of St 45 steel, the non-rotating disc is a sample with the test coating. The single path of the run is $150 \mathrm{~m}$. Load is $100 \mathrm{~N}$. The linear velocity of the lower disk is $1 \mathrm{~m} / \mathrm{s}$. The moment of friction is determined by the tribograms obtained at the installation. 
The breakdown voltage test of the phosphate coating is carried out at an alternating voltage. A plate with an electrical insulation coating is placed between the two electrodes, after which the voltage in the AC circuit slowly increases. The test is performed before the breakdown between the electrodes. The voltage that the voltmeter shows at this moment corresponds to the breakdown voltage.

\section{Results and discussion}

The lower porosity and grain size of coatings deposited from modified cold phosphating solutions allows them to resist the corrosive effect of the environment on the protected surface for longer $[19,20]$. The time until the first signs of corrosion appear in films obtained from modified cold phosphating solutions is 2 times less than in coatings obtained by the traditional method.

The data (Table 2) show that with increasing temperature, the protective ability of the coatings decreases, and when heated to $300{ }^{\circ} \mathrm{C}$, the films lose their protective properties.

Table 2. Test results of steel samples with phosphate coatings by drip method after heating

\begin{tabular}{|c|c|c|c|c|c|}
\hline \multicolumn{3}{|c|}{ Type of phosphate coating } & Traditional & Modified №1 & Modified №2 \\
\hline \multicolumn{3}{|c|}{$\begin{array}{l}\text { Control time immediately after } \\
\text { phosphating, sec }\end{array}$} & 60 & 130 & 135 \\
\hline \multirow{3}{*}{$\begin{array}{l}\text { Control time } \\
\text { after heating, } \\
\text { sec }\end{array}$} & \multirow{3}{*}{ 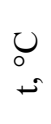 } & 100 & 50 & 95 & 112 \\
\hline & & 200 & 45 & 79 & 92 \\
\hline & & 300 & 1 & 2 & 2 \\
\hline
\end{tabular}

Along with the corrosion-protective properties, the adhesion strength of the phosphate coating to the metal and its adhesive properties are the most important criteria for evaluating the quality of phosphating. Studies have shown that phosphate films obtained from cold phosphating solutions on steel have high adhesive properties. As can be seen in Figure 2, the coatings are completely intact as a result of the test. The adhesion strength of the coating to the metal largely depends on the thickness of the coatings and varies inversely: the greater the thickness of the coatings, the less strong the coating.

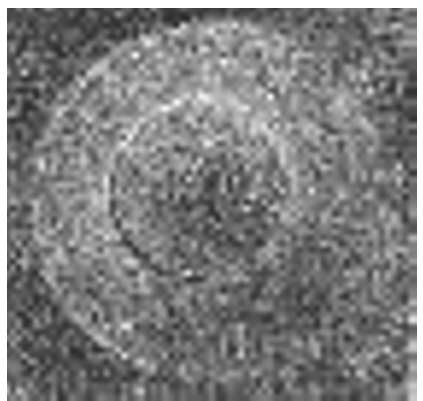

a)

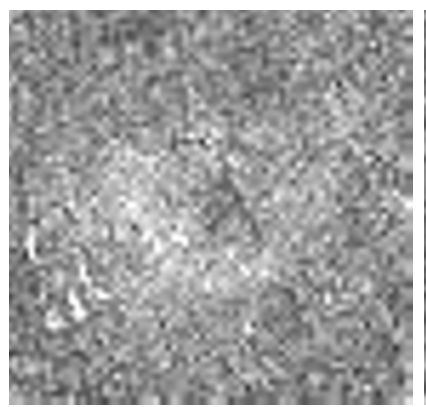

b)

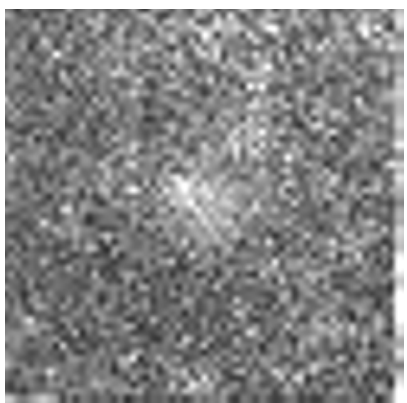

c)

Fig. 2. Surfaces of phosphate coatings on steel after impact testing: a) traditional coating; b) modified coating №1; c) modified coating №2.

During tests of the tribological properties of the films, it was found that the traditional coating shows an uneven distribution of the coefficient of friction over the thickness of the coating. At the surface of the product, the coating is softer and the coefficient of friction is higher, and the upper layers of the coating are harder and the coefficient of friction is correspondingly lower. The modified coating №1 is the most uniform in thickness of the 
studied ones. The friction is stable. The modified coating №2 is not uniform in thickness, and the friction is not stationary. Smaller damage areas (Fig. 3) and a small variation in the values of the coefficients of friction show that the modified coatings have a higher wear resistance. However, due to the low values of the friction coefficients and the heterogeneity of the coatings in thickness, phosphate films obtained from cold phosphating solutions are not suitable as wear-resistant coatings, but these coatings can be recommended for the protection of structural products.

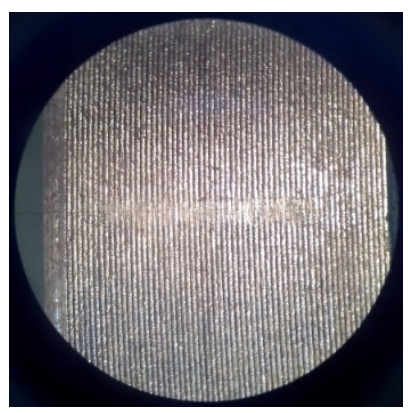

a)

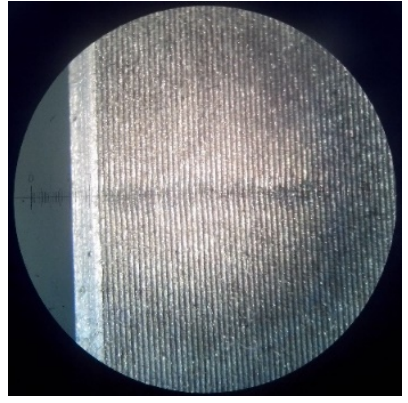

b)

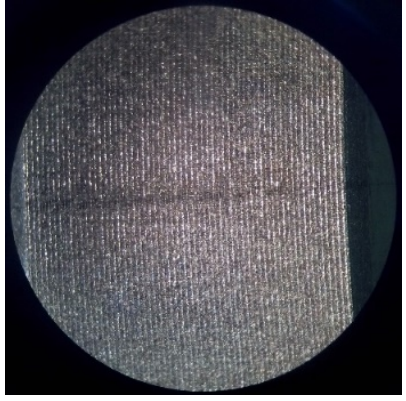

c)

Fig. 3. Images of damage after testing of phosphate coatings for wear resistance: a) traditional coating; b) modified coating №1; c) modified coating №2.

The results of tests to determine the breakdown voltage of phosphate coatings (Table 3) show that the modified coatings have higher electrical insulation properties compared to traditional coatings due to their better structure and more uniform distribution on the surface of the base metal. However, in comparison with the films obtained by hot phosphating, the results are not high. For such films, the average breakdown voltage is $250 \mathrm{~V}$, while the maximum voltage value for modified coatings does not exceed $200 \mathrm{~V}$. This difference in values is explained by the fact that the coatings obtained by cold phosphating are much thinner than the coatings obtained by hot phosphating.

Table 3. Breakdown voltage values of the phosphated steel surface

\begin{tabular}{|c|c|}
\hline Type of phosphate coating & Breakdown voltage, $\mathrm{V}$ \\
\hline Traditional & 110 \\
\hline Modified №1 & 200 \\
\hline Modified №2 & 184 \\
\hline
\end{tabular}

Modified phosphate coatings have better physical and mechanical properties compared to coatings obtained from a traditional cold phosphating solution. Despite the low wear resistance, phosphate coatings can be applied to the parts of machines that work on friction, to facilitate their burn-in, prevent jamming and reduce wear. Due to the high adhesion strength of phosphate coatings to metal, they are used in the automotive industry as a layer for priming and painting. The good electrical insulation properties of phosphate coatings allow them to be used to protect areas of parts and machines operating under voltage.

\section{References}

1. L.C. Deepa, S. Sathiyanarayanan, C. Marikkannu, D. Mukherjee, Effect of divalent cations in low zinc ambient temperature phosphating bath, Anti-Corrosion Methods and Materials, vol. 50, 4, pp. 286-290 (2003)

2. T.S.N.S. Narayanan, Surface pretreatment by phosphate conversion coatings - A review, Reviews on Advanced Materials Science, vol. 9, 2, pp. 130-177 (2005) 
3. K. Ravichandran, T.S.N. Sankara Narayanan, Studies on acceleration of low temperature zinc phosphating processes, Transactions of the Institute of Metal Finishing, vol. 79, 4, pp. 143-145 (2001)

4. A. Pakseresht, H. Alizadeh, A. Hanaei, B. Heidarshenas, A. Shahbazkhan, N.P. Ahmadi, The Effect of accelerator types on the phosphate Zn-\%12Ni electrodeposite coating, Material Science \& Engineering International Journal, vol. 2, 6, pp. 224-229 (2018)

5. Kirk-Othmer Encyclopedia of Chemical Technology (Wiley, 2000)

6. T.S.N. Sankara Narayanan, in Surfactants Polym. Coatings, Inks Adhes. (2020)

7. F. Fang, J. Yu, H. Gu, W. Cao, J. Jiang, Research of low-temperature fast phosphatizing solution for metal wire drawing, Dongnan Daxue Xuebao (Ziran Kexue Ban)/Journal Southeast University (Natural Science Edition), vol. 35, 2, pp. 253-256 (2005)

8. L.S. Karenina, G.S. Korzunin, R.B. Puzhevich, Effect of the Phosphate Component of Electrical Insulating Coating on the Magnetic Losses in Grain-Oriented Electrical Steel, Physics of Metals and Metallography, vol. 111, 1, pp. 21-24 (2011)

9. Z. Pawlak, P.K.D.V. Yarlagadda, R. Frost, D. Hargreaves, The mechanical strength of phosphates under friction-induced cross-linking, Journal of Achievements of Materials and Manufacturing Engineering, vol. 17, 1-2, pp. 201-204 (2006)

10. D.B. Freeman, Phosphating and metal pre-treatment. A guide to modern processes and practice (Cambridge, Woodhead, 1986)

11. D.P. Burduhos-Nergis, P. Vizureanu, A.V. Sandu, C. Bejinariu, Evaluation of the corrosion resistance of phosphate coatings deposited on the surface of the carbon steel used for carabiners manufacturing, Applied Sciences, vol. 10, 8, pp. 2753 (2020)

12. G. Gorecki, Iron phosphate coatings - composition and corrosion resistance, Corrosion 48, 7, pp. 613-616 (1992)

13. L. Fachikov, Y. Tumbaleva, D. Ivanova, B. Tzaneva, Technical note: Characterisation of amorphous phosphate coatings onto carbon steel surfaces, Transactions of the Institute of Metal Finishing, vol. 90, 6, pp. 330-333 (2012)

14. O. Girčienè, R. Ramanauskas, A. Martušiene, L. Gudaviciute, The effect of phosphate coatings on carbon steel protection from corrosion in a chloride-contaminated alkaline solution, Chemija, vol. 24, 4, pp. 251-259 (2013)

15. P. Pokorny, M. Novak, L. Mastny, P. Szelag, V. Brozek, Thermal stability of phosphate coatings on steel, Metalurgija, vol. 54, 3, pp. 489-492 (2015)

16. X. Wu, C. Chen, J. Hao, T. Zhao, H. Ma, Y. Lu, Z. Ren, Effect of Phosphating and Heat Treatment on Magnetic Properties of Fe-3.3Si-6.5Cr Soft Magnetic Composites, Journal of Superconductivity and Novel Magnetism, vol. 33, 6, pp. 1889-1897 (2020)

17. S. Ilaiyavel, A. Venkatesan, Investigation of wear coefficient of manganese phosphate coated tool steel, Tribology in Industry, 35, 1, pp. 69-73 (2013)

18. I. Sivakumaran, V. Alankaram, The wear characteristics of heat treated manganese phosphate coating applied to AlSi D2 steel with oil lubricant, Tribology in Industry, vol. 34, 4, pp. 247-254 (2012)

19. S. Fedosov, V. Roumyantseva, V. Konovalova, Phosphate coatings as a way to protect steel reinforcement from corrosion, MATEC Web Conferences, 298, p. 00126 (2019)

20. V. Konovalova, V. Rumyantseva, Corrosion protection of reinforcement with phosphate coatings, IOP Conference Series: Materials Science and Engineering, 890, p. 012091 (2020) 